\title{
Production methods of stacks and hydrogen with associated costs
}

\author{
Mr Daniel Symes and Dr Aman Dhir \\ Centre for Hydrogen \& Fuel Cell research \\ School of Chemical Engineering \\ University of Birmingham
}

Edgbaston

B15 2TT

UK

\begin{abstract}
There are currently approximately 50 million tonnes of hydrogen produced annually. This figure is expected to rise over the coming decades with the growth of a hydrogen economy. Hydrogen is currently \& predominately used in industry to produce ammonia, hydrogenation of fats and pharmaceutical manufacture [2]. All of these industries will continue to use hydrogen gas, so there will be an increased demand on the volume of hydrogen produced each year if the hydrogen economy is to succeed as an alternative form of energy. Consequently, hydrogen would need to be sourced from more than a single production pathway, and yet be sustainable. Each production pathway has unique benefits and disadvantages, such as cost of production and the purity of hydrogen produced. As a result new sustainable methods of producing hydrogen are being researched for optimisation and commercialisation. In this paper we examine traditional and new routes to production techniques and costs that are associated to them.
\end{abstract}




\section{Introduction}

Hydrogen is the most abundant element in the world, they only problem is it is always attached to something, thus liberating the element can prove to be a difficult task. Hydrogen is also a great energy store, it is not a fuel but an energy vector. It is an energy dense element and used correctly could be the source of power of the future. However, hydrogen is not solely used in the energy field, it is consumed and produced in a vast array of methods and processes. Of current hydrogen production, approximately $96 \%$ comes from fossil fuel sources, as shown in Figure 1. The feedstock's to these processes are finite and produce green house gases (GHGs) which is unsustainable and undesirable for the vision of a long term hydrogen economy.

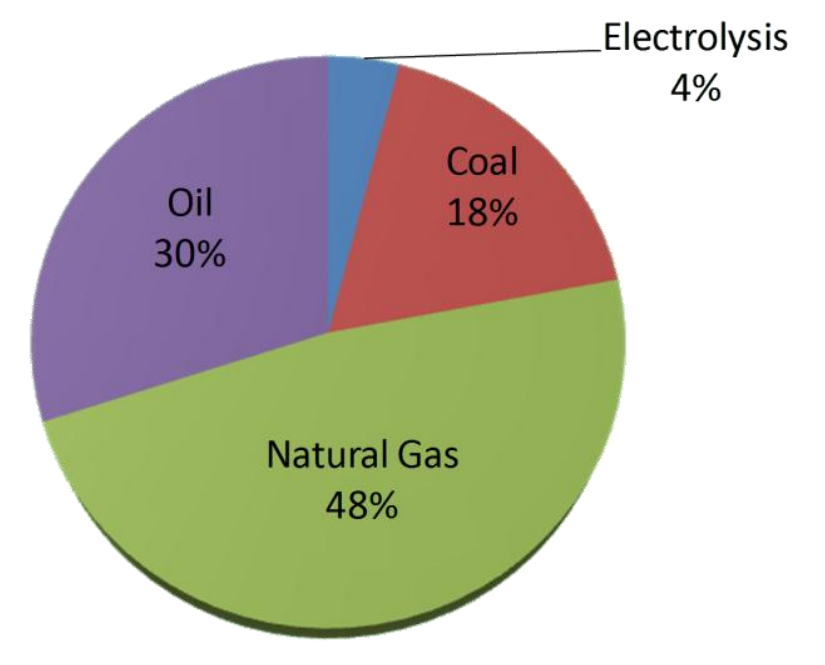

Figure 1: Current sources for Producing Hydrogen 


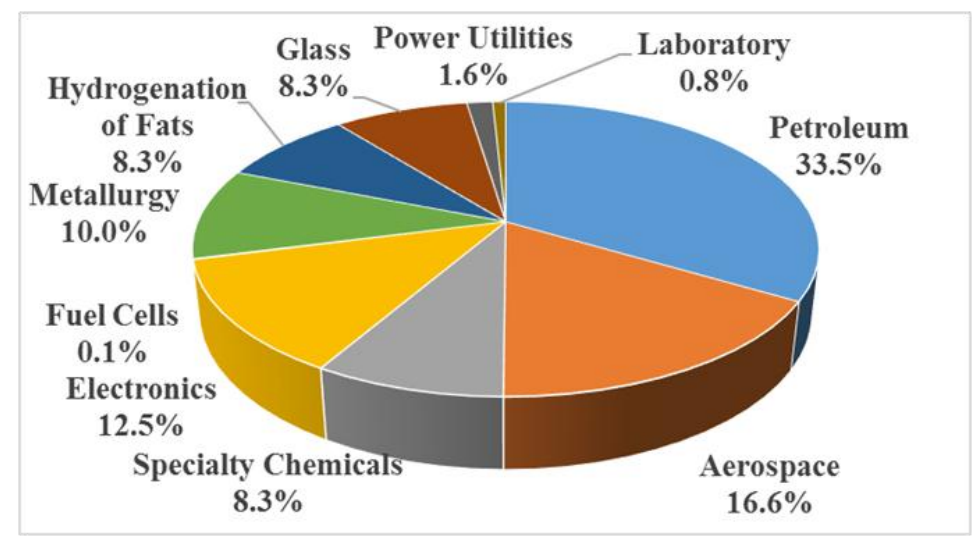

Figure 2: Representation of Uses of Hydrogen [2]

It can be seen that electrolysis contributes only to approximately $4 \%$ of global hydrogen production. Electrolysis being deemed a carbon free process - depending on the source of electricity. There reason why it only occupies $4 \%$ is due to the high economic cost of electrolysers compared to fossil fuel derived hydrogen techniques. Hydrogen produced from electrolysis currently only supplies niche applications (Figure 2), thus the demand is not driving the cost [4].

\section{Routes to production}

There are many routes to production, we consider here just the key industry methods and showcase alternative new ways in hydrogen production.

\section{Steam Methane Reforming}

Hydrogen production from methane is a well-established technology which produces almost half of all hydrogen produced today. When compared to other fossil fuels, methane (natural gas) is the most desirable, since it's widely available, relatively cheap and easy to handle [5]. Methane also has a high hydrogen-carbon ratio (4:1) of all fossil fuels (oil = 2:1; coal = 0.5:1).

The reaction mechanism is: 
A diagram illustrating the typical process for hydrogen production from steam methane reforming is illustrated in Figure 3.

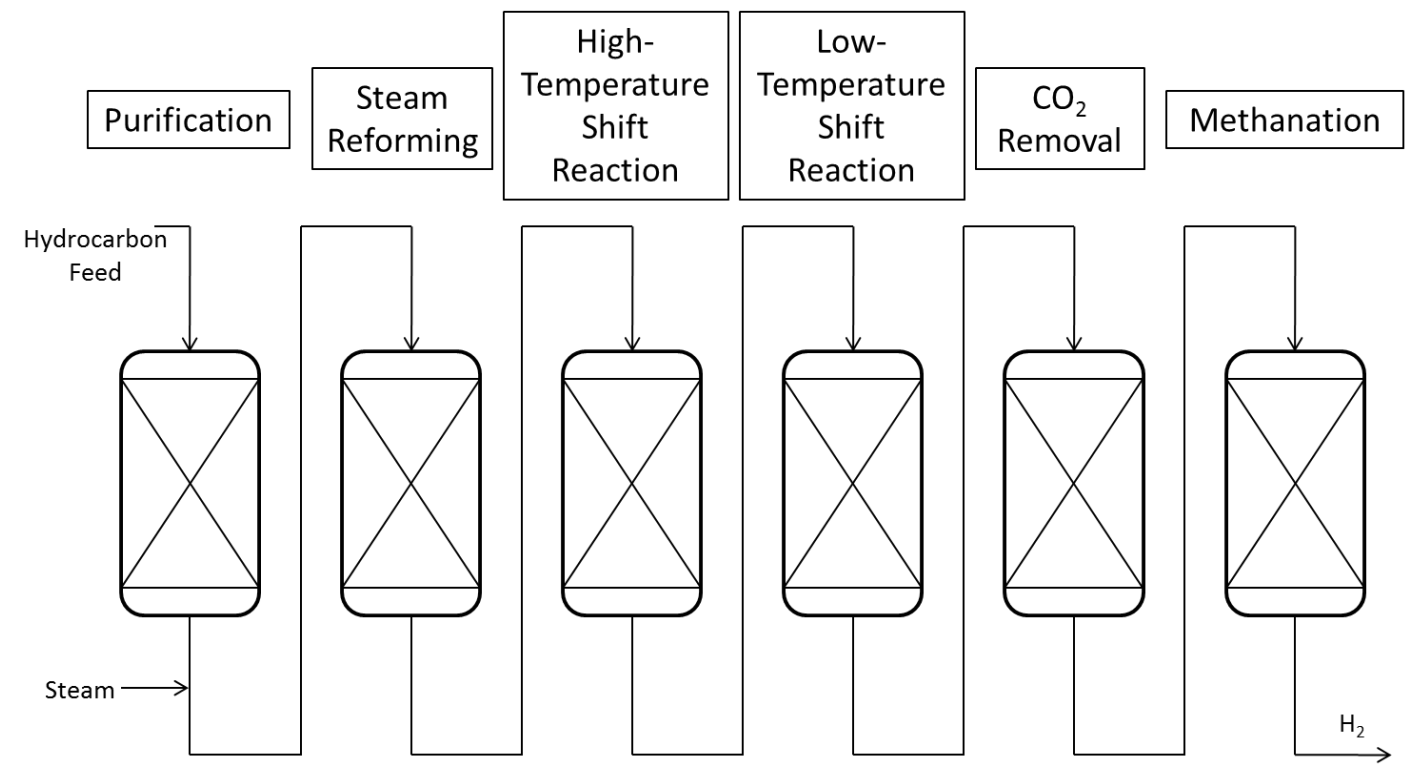

Figure 3: Process Flow Diagram for SMR

\section{Partial Oxidation}

Partial Oxidation (POX) is a process that is used to convert heavy liquid hydrocarbons e.g. oils and residues, to hydrogen. This process is similar to that of SMR, but involves the use of oxygen gas instead of steam to react the hydrocarbons with [6]. The reaction mechanism is outlined below [2].

$$
2 \mathrm{C}_{a} \mathrm{H}_{b}+a \mathrm{O}_{2} \rightarrow 2 a \mathrm{CO}+b \mathrm{H}_{2}
$$

The reaction is carried out at $1250{ }^{\circ} \mathrm{C}-1500^{\circ} \mathrm{C}$ and 3-13 MPa [7]. This high temperature and pressure removes the requirement for a catalyst. The typical thermal efficiency is $60-75 \%$ for methane fuel based on the higher heating values [8]. This process is illustrated in Figure 4. 


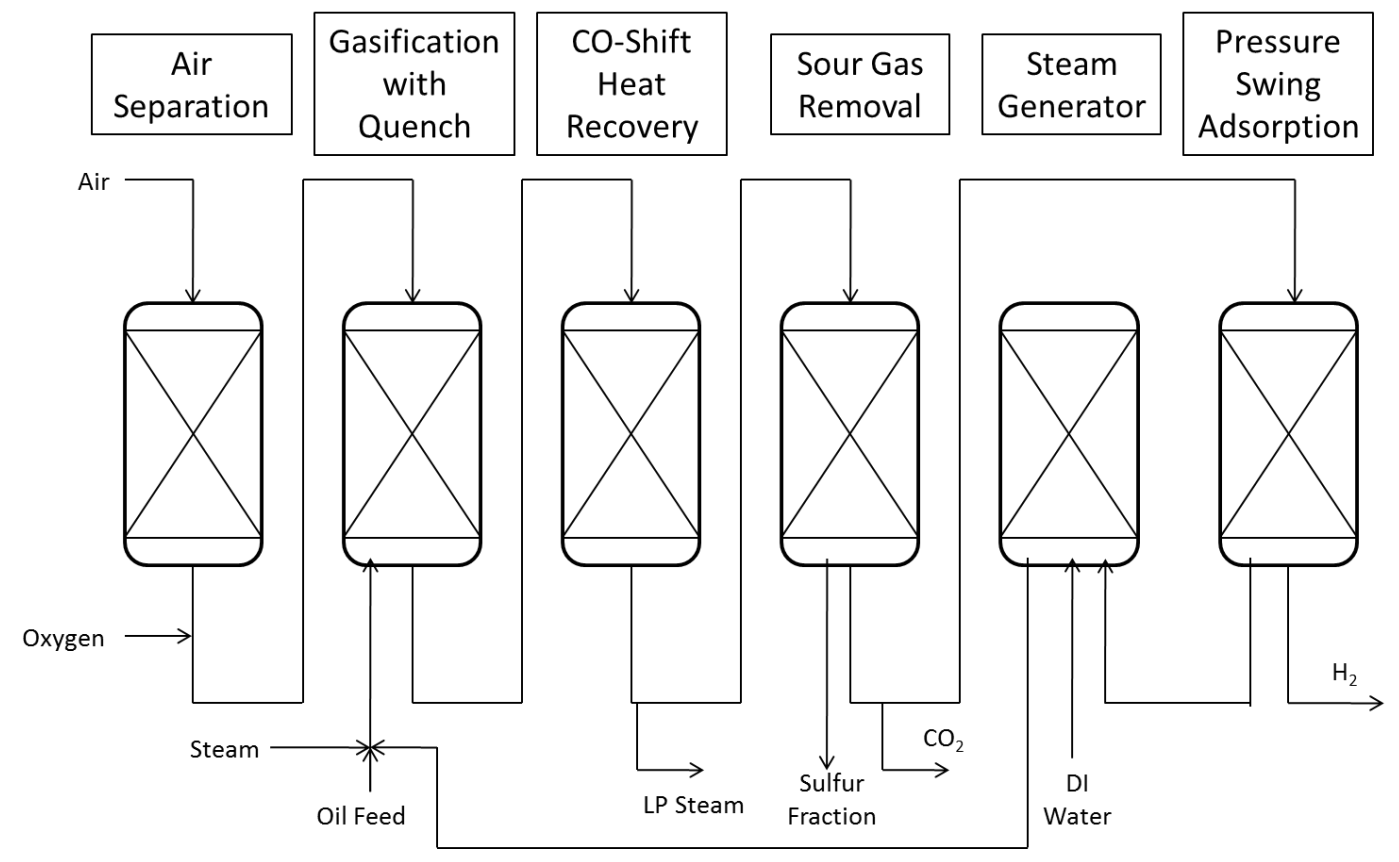

Figure 4: Process Flow Diagram for POX

\section{Coal Gasification}

With supplies of natural gas being depleted, coal is expected to be the preferred technology to meet our electrical energy needs for the future (there are estimated 150 years of coal reserves compared to estimated 50 years of natural gas) [8]. By definition, gasification is a process which converts solids into combustible gases in the presence of oxygen/air at high temperatures $>700^{\circ} \mathrm{C}[9]$. This reaction, where coal is the solid feedstock, produces, as with SMR and POX, syngas. The reaction mechanisms are detailed below [7].

Gasification

$$
\begin{gathered}
\mathrm{C}+\mathrm{O}^{0.5 \mathrm{O}_{2}} \rightarrow \mathrm{CO} \\
\mathrm{C}+\mathrm{H}_{2} \mathrm{O} \rightarrow \mathrm{CO}+\mathrm{H}_{2} \\
\mathrm{CO}+\mathrm{H}_{2} \mathrm{O} \rightarrow \mathrm{CO}_{2}+\mathrm{H}_{2}
\end{gathered}
$$

Water-Gas Shift

$$
\mathrm{CO}+\mathrm{H}_{2} \mathrm{O} \rightarrow \mathrm{CO}_{2}+\mathrm{H}_{2}
$$

Eq. 6

Purification

$$
\mathrm{CaO}+\mathrm{CO}_{2} \rightarrow \mathrm{CaCO}_{3}
$$


The syngas is then placed under water-gas shift reactions to produce a suitable yield of hydrogen. Purification involves the use of lime $(\mathrm{CaO})$, to separate carbon from the hydrogen [10].

A diagram illustrating the basic process for hydrogen production from coal gasification is illustrated in Figure 5.

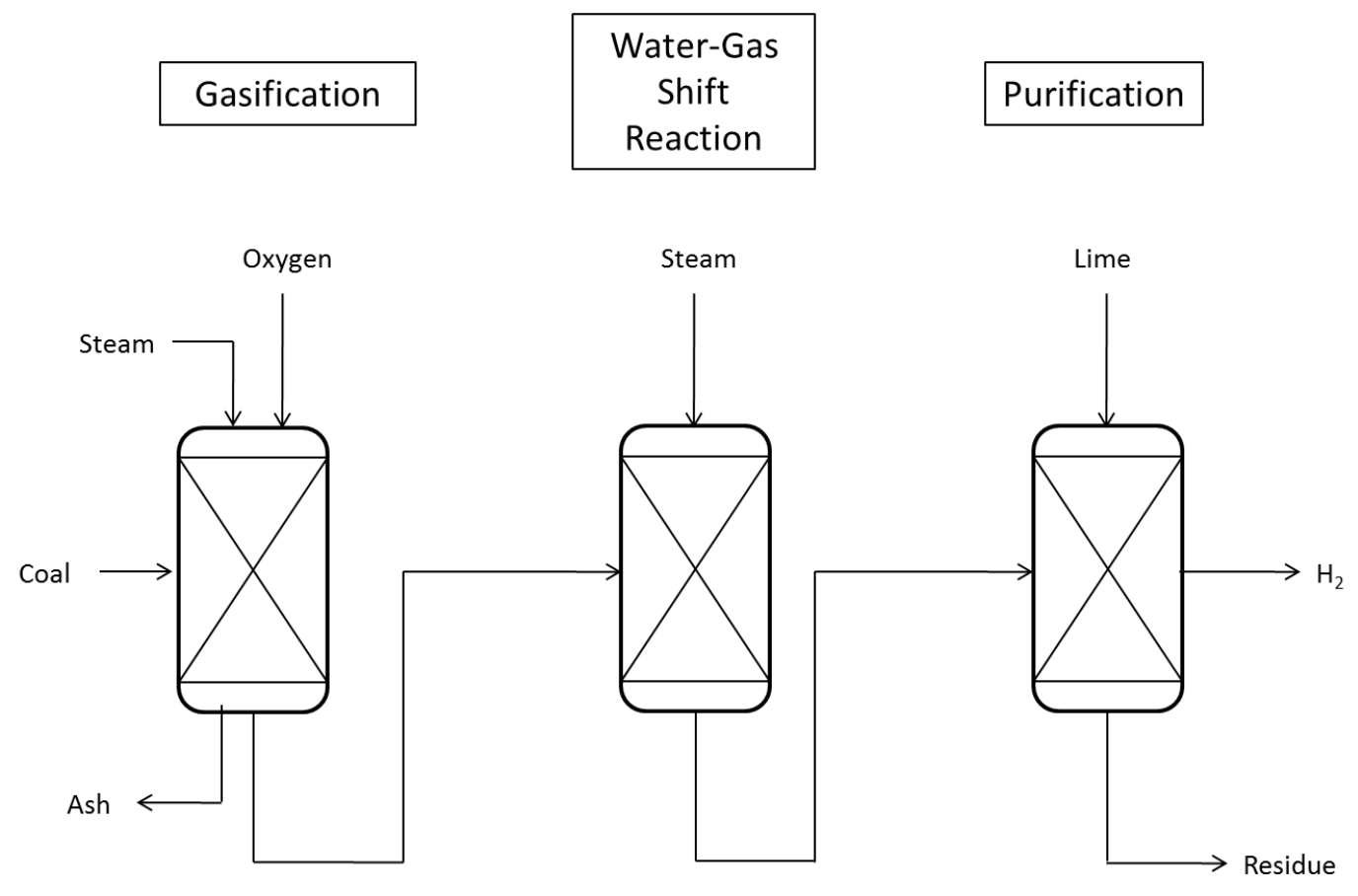

Figure 5: Process Flow Diagram of Coal Gasification

Coal gasification produces hydrogen at a faster rate than SMR and POX, but the capital costs are greater due to the pre-treatment required on the coal (milling, desulphurising) and the increased number of particulates in the syngas produced [7]. These cleaning processes are a vital component of the gasification process, since the restriction of catalyst poisoning in the reactor, and the purity of syngas produced are of vital importance to meet the preset requirements. 


\section{Photolysis \& Photocatalysis}

Photolysis is a process for producing hydrogen from solar energy through photosynthesis. The process utilises energy from the Sun to split water and produce hydrogen [11]. The reaction occurs in the thylakoid membrane in the chloroplast [11]. This is where the energy in the light is converted to chemical energy. Water molecules oxidise to produce hydrogen and oxygen gases, and the electrons are transferred through a membrane to Adenosine Triphosphate (ATP). This passes chemical energy in the cells for metabolism. This ATP then undergoes hydrolysis to produce orthophosphate (PI) which is an inorganic phosphate [7]. The reaction mechanism is illustrated in the diagram (Figure 6).

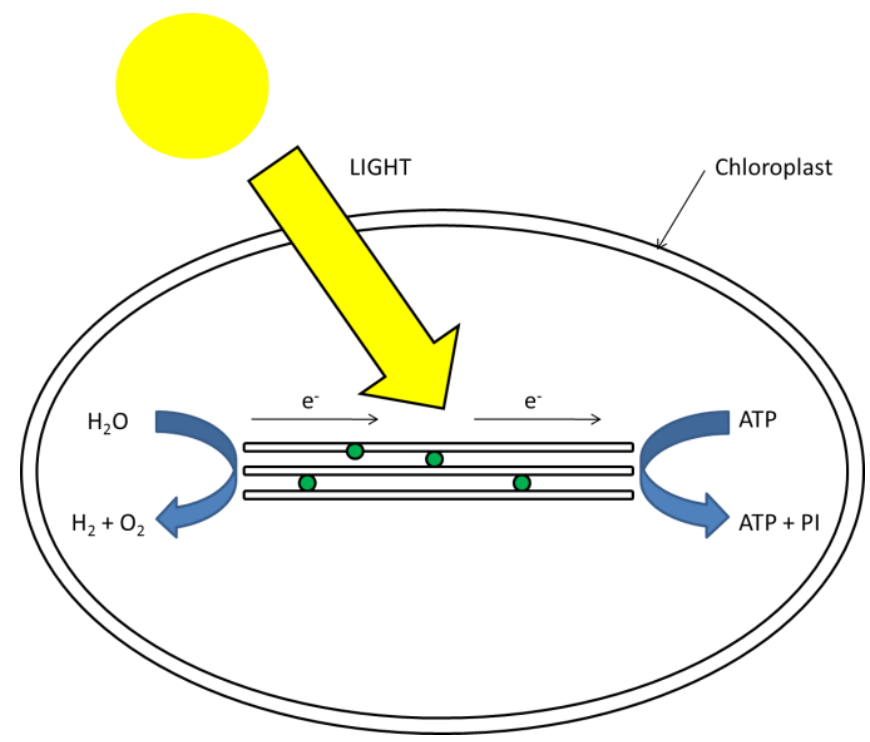

Figure 6: Reaction Mechanism for Photolysis

Similarly to photolysis, photocatalysts for splitting water directly to produce hydrogen have been considered. The photocatalysts absorb light from the Sun and generate free electrons and lattice vacancy holes, which are capable of performing reduction and oxidation (redox) reactions [8]. The electrons are transferred from the water to oxygen gas reaction to the hydrogen evolution reaction. Many catalysts have been researched which include $\mathrm{TiO}_{2}$, $\mathrm{RuO}_{2}, \mathrm{CdS}_{2}$ and cobalt. These catalysts continue to be an active area of research and as of 
yet are not commercially viable to produce hydrogen on a large-scale [7]. The reaction mechanism is illustrated in Figure 7.

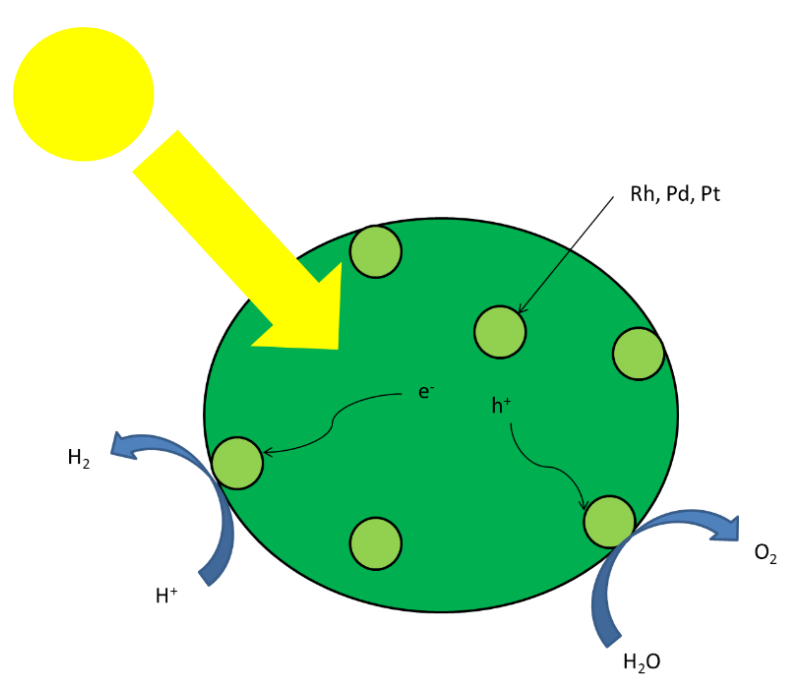

Figure 7: Reaction Mechanism of Photocatalysts

These bio-derived sources of hydrogen provide a sustainable feedstock of 'fuel' to produce hydrogen and are seen by many as a likely method for producing hydrogen once the fossil fuel feedstocks for hydrogen production have been depleted.

\section{Water Electrolysis}

Electrolysis is defined as applying an electrical current to split compounds [12]. Water splitting occurs when a direct current is passed between an anode and a cathode submerged in water separated by a solid electrolyte or a non-electrically conducting aqueous electrolyte to transport ions and complete the electrical circuit [13].

Water electrolysis requires two inputs, electrical energy and water. If the electrical energy is supplied from renewable resources, 'Green' hydrogen i.e. greenhouse gas emission free, is produced. Water is also in "limitless" supply, there are approximately $1.26 \times 10^{21}$ litres of 
water on Earth [14]. It is not geographically limited either, which could lead to the fall of energy poverty globally.

Water, the basis of electrolysis, is a very stable molecule with a heat of formation of $285.83 \mathrm{~kJ} / \mathrm{mol}$ under standard conditions [15]. To enhance the conductivity of the water based solution, electrolytes, which consist of ions with high mobility, are added. The purity of hydrogen produced from electrolysis is very high (> 99.9999\%), this requires less gascleaning processes than fossil fuel derived hydrogen needs. For applications that require ultra-pure hydrogen, electrolysis is currently the only method of hydrogen production that can meet the stringent requirement. Fuel cells are predicted to play a vital role in the future automotive industry, portable and stationary power sectors, therefore a supply chain of high purity hydrogen is required to fuel these electrochemical devices.

An application for electrolysis is in energy storage. During electricity generation at power stations, nuclear power plants, renewable energy sources (wind turbines, hydroelectric power) there may be an excess in electrical energy than is required by the grid. In this case, the excess electricity can be converted to hydrogen through electrolysis and stored. This hydrogen energy can then supplied into the grid via fuel cells to produce electricity when the consumer demand is higher.

There are three main types of electrolysers; alkaline, polymer electrolyte membrane (PEM), and solid oxide (SO).

\section{Alkaline electrolysers}

Alkaline Electrolysis is an established technology, with the first concepts of electrolysis carried out using acid/alkaline electrolytes. Alkaline solutions are the preferred electrolyte in modern systems due to less corrosion caused to the electrodes, which acidic solutions cause [16]. A schematic of alkaline electrolysis is illustrated in Figure 8. 


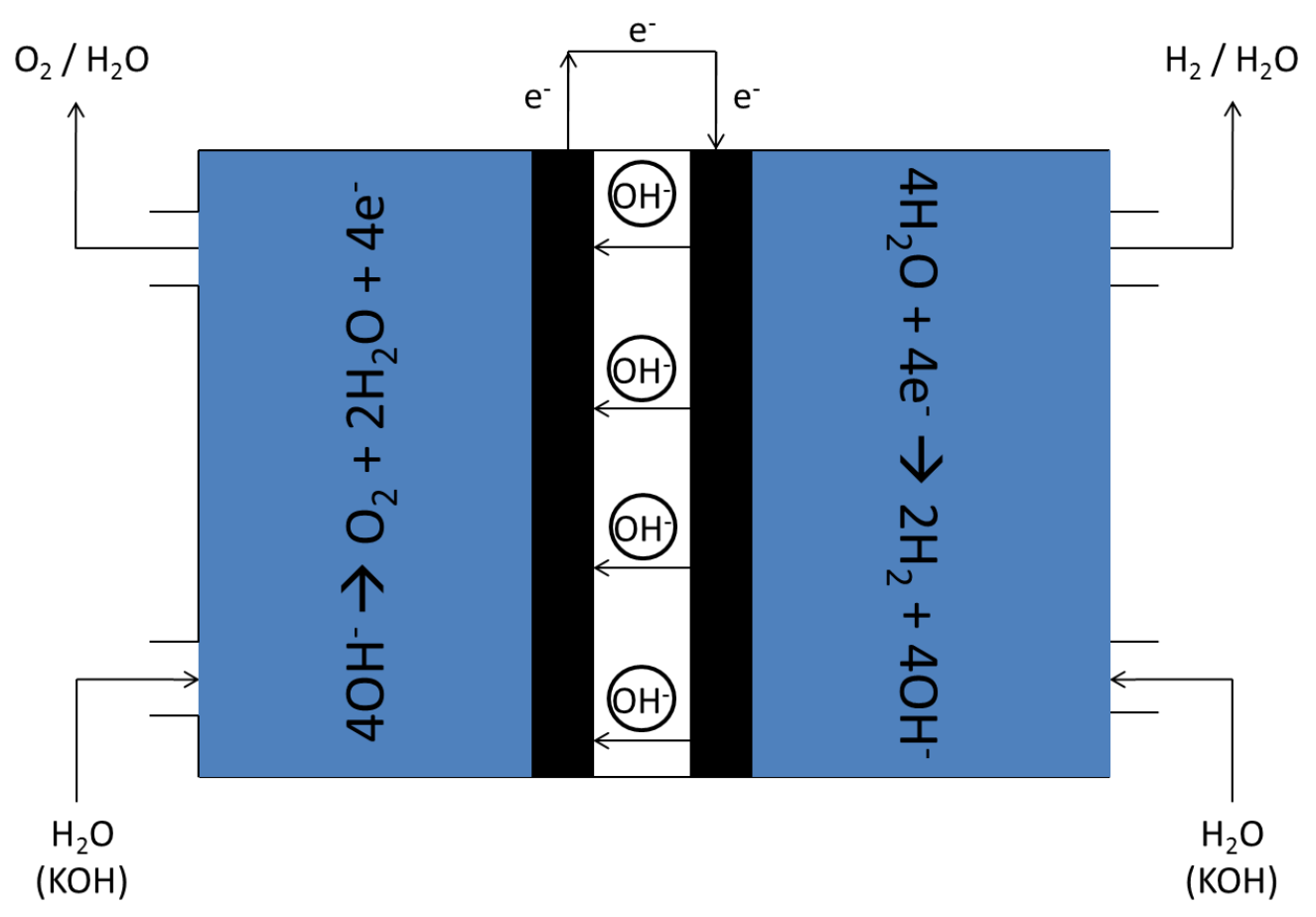

Figure 8: Schematic of Alkaline Electrolysis

The main electrolytes used are potassium hydroxide $(\mathrm{KOH})$ and sodium hydroxide $(\mathrm{NaOH})$, and usually consist of 25-30 weight $\%$ in industrial electrolysis units [14]. The liquid electrolyte enables the conduction of ions between the electrodes in the solution and is not consumed in the reaction. Concentrations of up to 50 weight $\%$ can be used, but this results in faster rates of electrode degradation [7].

The most commonly used materials of electrodes for alkaline electrolysis are nickel and stainless steel; due to their high conductivity and low cost $[15,17]$. The operating temperature during electrolysis is approximately $80^{\circ} \mathrm{C}$ and can go up to $150^{\circ} \mathrm{C}$. Temperatures higher than this can result in rapid degradation of electrodes from the caustic solution. Alkaline electrolysers can operate and produce hydrogen at 5-30bar pressure [18].

Alkaline electrolysers typically operate with current densities (current per surface area) between $100-4000 \mathrm{~mA} / \mathrm{cm}^{2}$ [15]. Efficiencies of these electrolysers are typically $64-70 \%$, and production ranges from $10-100 \mathrm{~m}^{3} /$ hour [15]. 
The reaction mechanisms are
Cathode
$4 \mathrm{H}_{2} \mathrm{O}+4 \mathrm{e}^{-} \rightarrow 2 \mathrm{H}_{2}+4 \mathrm{OH}^{-}$
Eq. 9
Anode
$4 \mathrm{OH}^{-} \rightarrow \mathrm{O}_{2}+2 \mathrm{H}_{2} \mathrm{O}+4 \mathrm{e}^{-}$
Eq. 10
Overall
$2 \mathrm{H}_{2} \mathrm{O} \rightarrow 2 \mathrm{H}_{2}+\mathrm{O}_{2}$
Eq. 11

\section{PEM electrolysers}

PEM electrolysis technology uses a solid polymer electrolyte (SPE) membrane to split water into its constituent elements [19]. As a consequence no liquid electrolyte is required which enables safer handling of the electrolyte for the end user [20].

The membrane is non-electrically conductive and proton conducting. The standard membrane material used in PEM electrolysis is Nafion ${ }^{\circledR} 117$ which is produced by DuPont [21]. Nafion ${ }^{\circledR}$ is a co-polymer of perfluorinated vinyl-ethersulfonyfluoride and tetrafluorethylene. Perfluorinated sulfonic acid (PFSA) membranes have proved to be highly resistant to the oxidative nature of oxygen.

The PEM is part of the membrane electrode assembly (MEA) which consists of highly expensive platinum catalyst layers on either side of the PEM. Platinum is highly susceptible to poisoning from cation impurities commonly found in natural water [23]. As a result ultrapure water, (minimum $10 \mathrm{M} \Omega$ ) is a vital requirement for long term PEM electrolysis [14]. Poisoning of the catalyst layer results in an irreversible drop in electrochemical performance and the high cost of platinum makes degradation undesirable [12]. A schematic of PEM electrolysis is illustrated in Figure 9. 


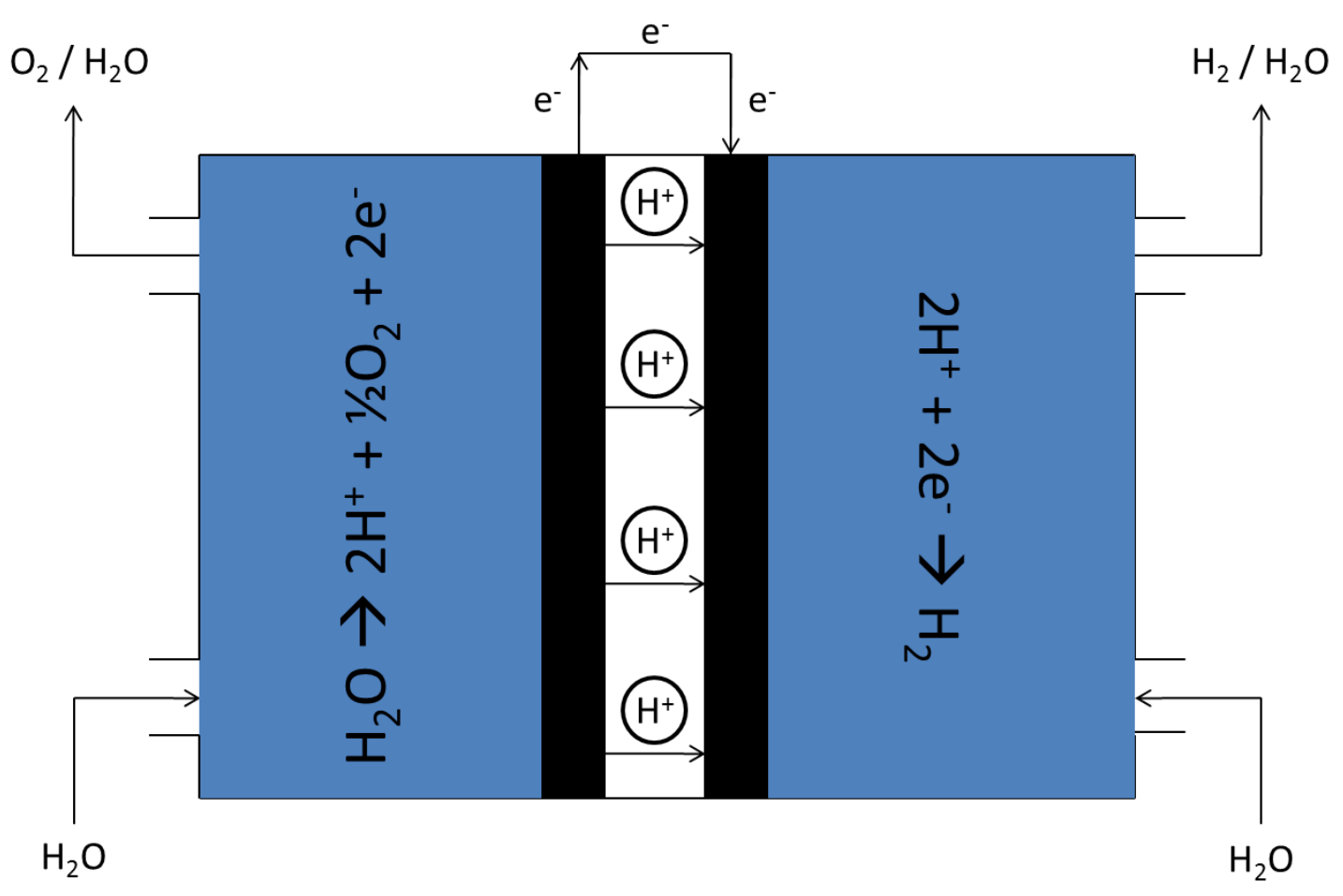

Figure 9: Schematic of PEM Electrolysis

At the anode catalyst layer, water is split into oxygen, electrons and protons by applying a direct current (DC) [24]. The oxygen gas evolved leaves to the atmosphere above the anode. The electrons pass through the external circuit to the cathode and the protons pass through the PEM [13]. On the cathode electrocatalysts the electrons from the external circuit and protons passed through the membrane recombine to produce hydrogen gas [25].

PEM electrolysers operate with current densities of $>1600 \mathrm{~mA} / \mathrm{cm}^{2}$ and efficiencies of 5585\% [26]. Nafion membranes suffer from degradation at high temperatures, therefore the operating temperature of PEM electrolysis has to be kept $<100^{\circ} \mathrm{C}$ [27].

The reaction mechanisms are

Cathode

$4 \mathrm{H}^{+}+4 \mathrm{e}^{-} \rightarrow 2 \mathrm{H}_{2}$

Eq. 12

Anode

$2 \mathrm{H}_{2} \mathrm{O} \rightarrow \mathrm{O}_{2}+4 \mathrm{H}^{+}+4 \mathrm{e}^{-}$

Eq. 13 


\section{Solid oxide electrolysers}

Solid oxide electrolysis, also known as steam electrolysis, introduces the concept of electrolysis at higher temperatures $\left(700-1000^{\circ} \mathrm{C}\right)$ than alkaline and PEM electrolysis. This enables a more efficient electrolysis system, since heat supplies a proportion of the energy required to split water [7]. In addition to this, overpotential is also reduced as a direct result of the higher temperature [28]. One of the main disadvantages of electrolysis, as a production pathway for large scale hydrogen production, is the high electrical energy consumption. The decrease in electrical energy requirement provides a more economically realistic process. This makes steam electrolysis thermodynamically and kinetically more favourable than its low temperature counterparts [14].

Steam electrolysis uses an oxide conducting electrolyte to split steam into hydrogen and oxygen. Steam enters the electrolyser on the cathode side of the cell and reacts with electrons from the external circuit to produce hydrogen and oxide ions. The oxide ions transport through the electrolyte to the anode where the oxide ions are oxidised to oxygen gas and electrons, which are transported through the external circuit to the cathode. A schematic of SO electrolysis is illustrated in Figure 10. 


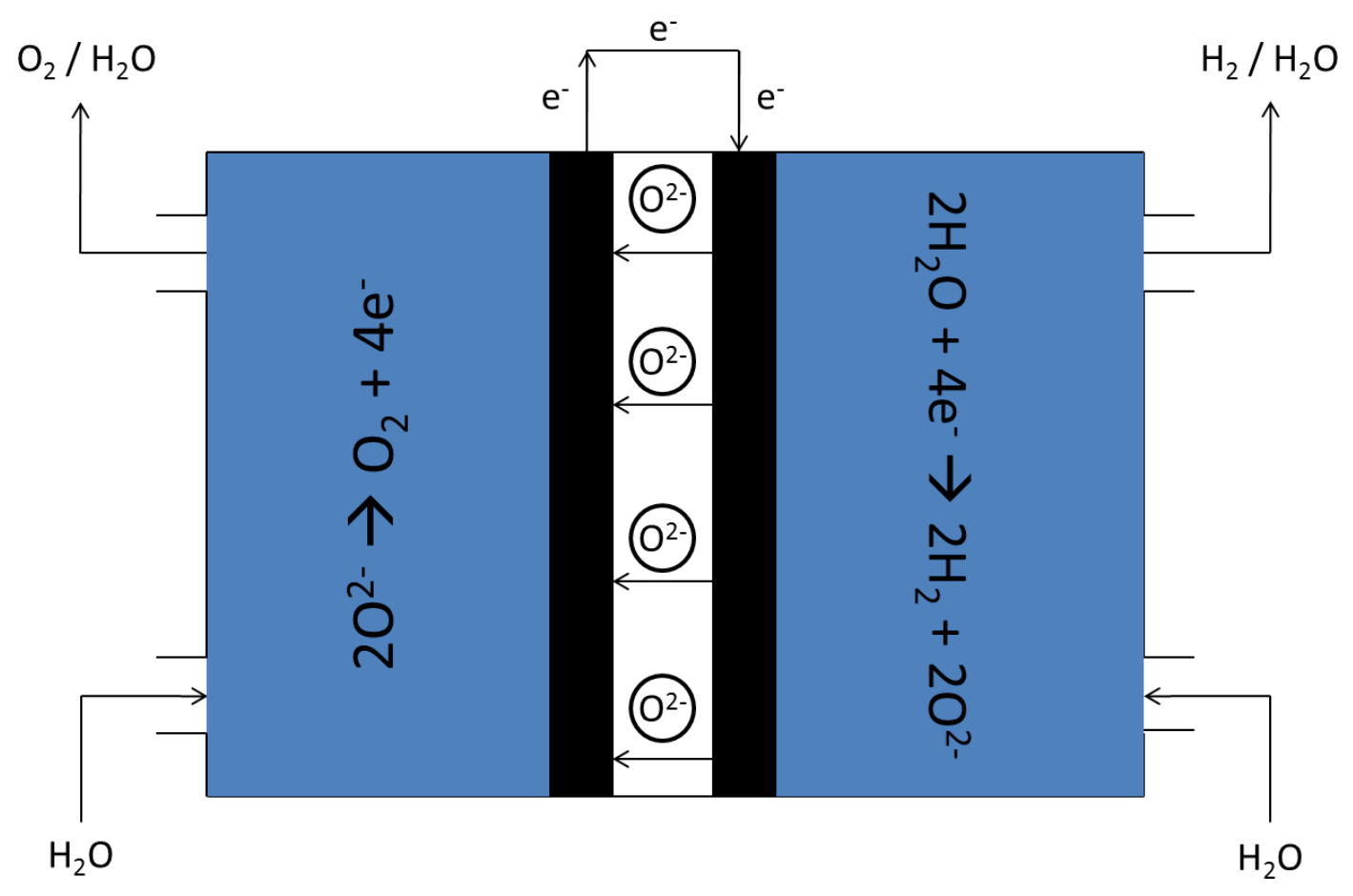

Figure 10: Schematic of Solid Oxide Electrolysis

Oxide conducting electrolytes are usually zirconia $\left(\mathrm{ZrO}_{2}\right)$ stabilised by $\mathrm{Y}_{2} \mathrm{O}_{3}, \mathrm{CaO}$ or $\mathrm{MgO}$ [29]. The electrode materials for the cathode are usually nickel (Ni) based yttria stabilised zirconia (YSZ), and the anode material is lanthanum strontium manganate (LSM) [7].

Small scale SO electrolysis cells have been produced, which have demonstrated hydrogen production efficiencies of 70-90\% [7]. This is much higher than its low temperature (alkaline and PEM) electrolyser equivalents.

A method of decreasing the electrical energy requirement for steam electrolysis even further is through the use of methane. In this process, the air on the anode side is replaced by methane, which reduces the open-circuit voltage and therefore the electrical energy consumption [30].

The reaction mechanism is 


\section{Summary of Technologies}

A summary of the various hydrogen technologies including their feedstocks, efficiencies and maturities is shown in Table 1.

Table 1: Summary of Hydrogen Production Technologies (Reproduced from [8])

\begin{tabular}{|c|c|c|c|}
\hline Technology & Feedstock & Efficiency & Maturity \\
\hline $\begin{array}{l}\text { Steam Methane } \\
\text { Reforming }\end{array}$ & Hydrocarbons & $70-85 \%^{a}$ & Commercial \\
\hline Partial Oxidation & Hydrocarbons & $60-75 \%{ }^{a}$ & Commercial \\
\hline Biomass Gasification & Biomass & $35-50 \%{ }^{\mathrm{a}}$ & Commercial \\
\hline Photolysis & Sunlight + Water & $0.5 \%^{b}$ & Long Term \\
\hline Dark Fermentation & Biomass & $60-80 \%{ }^{c}$ & Long Term \\
\hline Photo Fermentation & $\begin{array}{c}\text { Biomass + } \\
\text { Sunlight }\end{array}$ & $0.1 \%^{d}$ & Long Term \\
\hline $\begin{array}{l}\text { Thermochemical } \\
\text { Water Splitting }\end{array}$ & Water + Heat & N/A & Long Term \\
\hline $\begin{array}{c}\text { Photoelectrochemical } \\
\text { Water Splitting }\end{array}$ & Water + Sunlight & $12.4 \%{ }^{\mathrm{e}}$ & Long Term \\
\hline Alkaline Electrolysis & Water + Electricity & $50-60 \%{ }^{f}$ & Commercial \\
\hline PEM Electrolysis & Water + Electricity & $55-70 \%^{f}$ & Near Term \\
\hline $\begin{array}{l}\text { Solid Oxide } \\
\text { Electrolysis }\end{array}$ & $\begin{array}{c}\text { Water + Electricity } \\
+ \text { Heat }\end{array}$ & $40-60 \%^{g}$ & Medium Term \\
\hline
\end{tabular}

${ }^{a}$ Thermal efficiency, based on the higher heating values.

${ }^{\mathrm{b}}$ Solar to hydrogen via water splitting and does not include hydrogen purification.

${ }^{c}$ Percent of 4 mole $\mathrm{H}_{2}$ per mole glucose theoretical maximum.

${ }^{\mathrm{d}}$ Solar to hydrogen via organic materials and does not include hydrogen purification

${ }^{\mathrm{e}}$ Solar to hydrogen via water splitting and does not include hydrogen purification

f Lower heating value of hydrogen produced divided by the electrical energy to the electrolysis cell.

${ }^{g}$ High temperature electrolysis efficiency is dependent on the temperature the electrolyser operates at and the efficiency of the thermal energy source. For example, SOEC operating 
from advanced high temperature nuclear reactors may be able to achieve up to $60 \%$ efficiency. If thermal energy input is ignored, efficiencies up to $90 \%$ have been reported [40].

\section{Electrolyser Stack components}

\section{Electrodes}

The choice of material for the electrode is governed by numerous factors. The desired requirements are good electrical conductance, high corrosion resistance and minimum overvoltage [31, 32]. The cathode and anode materials in alkaline systems are usually made of nickel or nickel plated metal on which a catalyst can be applied. The catalyst can be noble metals like platinum, rhodium or iridium, but a large selection of non-noble catalysts is also available [18, 33, 34].

The application of precious-metal catalysts, such as platinum, enhances the electrode processes considerably and allows it to proceed more rapidly than on just nickel, but the extra cost of the precious metal is usually not considered justified $[35,36]$. Gold can be used, while the precious metals such as platinum, rhodium, iridium, are popularly considered catalysts. When platinum is used, a large surface area can be obtained by the use of platinum black, a finely divided powder of platinum metal particles which can be coated on the electrode surface [36, 37].

\section{Electrolytes}

\section{Solid Electrolyte}

A new design of an alkaline electrolyser is the implementation of a zero-gap electrode system with an $\mathrm{OH}^{-}$conducting membrane. In this the electrodes are joined to either side of membrane surface which acts to reduce the potential drop between the cathode and anode [38]. Zero-gap cells with a porous separator can be constructed but they are predicted to have a larger voltage drop leading to lower current density operation and subsequently larger electrolysis systems [39]. 


\section{Liquid Electrolyte}

Most commercial electrolysers use alkaline solutions (potassium or sodium hydroxide) as the electrolyte. Energy consumption during water electrolysis can be significantly reduced by adding small quantities of acidic/basic compounds which consist of ionic activators which reduce the resistivity of water [18]. Ionic liquids which are organic compounds are liquids solely made up of cations and anions and as a result possess excellent ionic conductivities and stability [36].

In industrial electrolyser applications, these parameters can be met by the use of a strong acid (e.g. sulphuric acid) or a strong alkali (e.g. potassium hydroxide). The majority of salts decomposed under electrolysis at voltages typical in an electrolyser cell. Acid electrolytes present the problems of severe corrosion and are not often selected for electrolysers [40]. As a result most industrial electrolysers operate with an alkaline electrolyte solution. High conductivity occurs in $\mathrm{KOH}$ solutions at approximately $30 \%$ concentration and this is the industrial standard concentration used [36].

\section{Separators}

It is positioned between the cathode and anode and prevents the electrodes from touching each other and causing an electrical short. It also prevents the hydrogen and oxygen gases from mixing together inside the cell if this is desired. The separator must consist of a porous diaphragm or matrix through which the electrolyte solution can pass allowing an ionic conducting path from the anode to the cathode. These pores must remain full of liquid at all times so the product gases cannot penetrate them. Additionally, the separator material must be corrosion resistant to the electrolyte in the presence of hydrogen or oxygen gas and it must be structurally stable for the operational lifetime of the cell so that the pores do not collapse $[36,41]$. 
In order to keep the ionic resistance of the cell low, the separator is usually in the form of a thin sheet, in which the thickness is determined by mechanical strength and gas crossover limitations. Asbestos has commonly been used for the separator material in alkaline electrolysers. Woven asbestos cloth and matted asbestos fibres are both utilised in commercial cells [41].

\section{PEM Electrolysis}

An MEA consists of the solid polymer electrolyte coated on either side with electrocatalyst to form a catalyst coated membrane (CCM) pressed between two porous current collectors. As well as acting as an electrolyte the MEA acts as a barrier between the half-cell reactions as only protons are conducted through it. This ensures that hydrogen and oxygen do not recombine to form water [42].

\section{Electrocatalysts}

It is important that the electrodes are resistant to corrosion as well as resist attack from the gases produced and water. Since the gases need to be expelled from the electrodes they must be built with a large surface area. They need to have a porous matrix with a low pressure drop and must have a high electrical conductivity to prevent undesired heat being produced and to avoid an imbalanced current flow. The cost and duration of the electrode must be considered to compromise between the capital cost and suitable longevity of the electrolyser cell $[22,43-45]$.

\section{Hydrogen Evolution Reaction}

At the cathode hydrogen evolution reactions take place (HER). Platinum black was the catalyst first used but future development found this catalyst to provide too small a surface area which led to the requirement of finding greater platinum concentration $[22,46,47]$. The most commonly used catalyst for HER is platinum particles on a carbon black support [12, 48, 49]. Platinum a very good electrocatalyst for PEM electrolysis as it is resistant to acidic 
corrosion and is capable of withstanding high temperatures and voltages which are used [22, $24,31,43,50]$.

The carbon black support is powder based which provides a large surface area to volume ratio and subsequent large number of active sites for adsorption. Chemisorbed functional groups of quinones, carboxyls, hydroxyls and phenols are present as a result and leads to an increase platinum adsorption. The platinum nanoparticles are distributed over the active sites of the carbon black (Pt/C) and surface areas of up to $1500 \mathrm{~m}^{2} / \mathrm{g}$ can be achieved [51-53]. $\mathrm{Pt} / \mathrm{C}$ exhibits high mass transfer and also sustains good osmotic balance to reduce flooding in the cell. The catalytic performance of the noble metals: platinum, palladium, rhenium, iridium, osmium, ruthenium and nickel; have been studied and discovered that platinum showed the best electrochemical catalyst behaviour irrespective of it being highly expensive and in short supply [54].

Since OER is rate determining it is most effective to reduce the amount of platinum in the cathode rather than the iridium at the anode. This is due to the higher ratio of $\mathrm{H}^{+} / \mathrm{H}_{2}$ at the cathode compared to the ratio of $\mathrm{H}_{2} \mathrm{O} / \mathrm{O}_{2}$ at the anode $[12,51,53]$. Combining platinum with cheaper PGMs such as palladium to make a Pt/Pd alloy, gives rise to significant reductions in the cost of the catalyst without reducing the efficiency.

\section{Oxygen Evolution Reaction}

At the anode oxygen evolution reactions (OER) takes place. On first conception platinum was used as the electrocatalyst for the anode also, but as shown in more recent research that iridium exhibited a higher rate of oxygen evolution [55]. Platinum obstructed the OER as it formed an oxide film that would decrease catalytic performance [40]. Iridium exhibited desirable characteristics as an anode catalyst compared to that of palladium, ruthenium, platinum, gold, rhenium and niobium. Better catalysts could be manufactured using mixtures of iridium and other noble metals as well as oxides derivatives of each [45]. Iridium oxide 
and ruthenium oxide are sometimes used as the catalyst but both metal oxides suffered from corrosion. This led to the use of an iridium-ruthenium alloy that would be used as a catalyst on a carbon black support $[56,57]$.

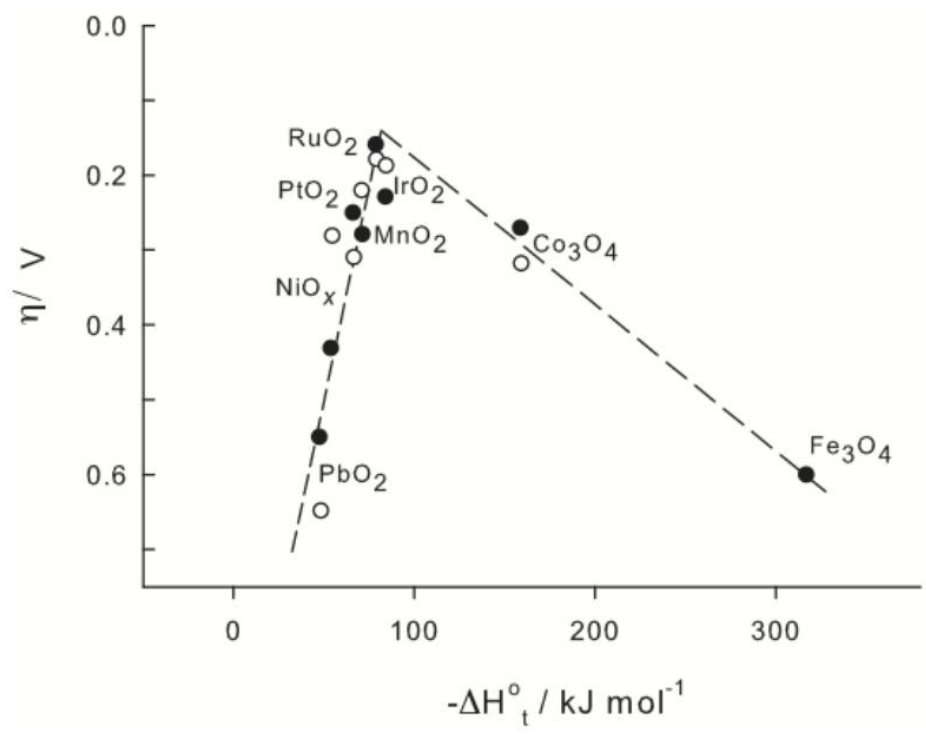

Figure 11: Volcano-plot of electrocatalytic activity of different transition metal oxides [58]

The OER is the rate determining step and the reaction under sees adsorption, charge transfer, and desorption. A high Ir-O bond strength enables fast adsorption but slow desorption. A middle ground is required to gain a transitional bond strength that favours each of the reaction steps. A high charge transfer rate is reliant on a high density of electron states on the adsorbed species. Figure 11 compares the different electrocatalytic activities of the metal oxides used at the anode. It shows that $\mathrm{IrO}_{2}$ and $\mathrm{RuO}_{2}$ display the best catalytic properties [59-63].

\section{Ionomer \& Proton Exchange Membrane}

In recent years PEM electrolysis cells are manufactured through the catalyst coated membrane $(\mathrm{CCM})$ process and they have a layer of ionomer present with ionic transport properties (e.g. Nafion® solution) applied to the electrocatalytic layers [20, 64-66]. The ionomer layer has three main functions [67]: 
1. It acts as a conductor to promote proton transport from the bulk of the catalyst layer to the membrane. This results in decreased Ohmic losses and so enhance the overall efficiency of the electrolyser.

2. It acts as a binder to provide a mechanically stable 3D structure for the catalyst layer with gas channels which enhances durability.

3. It acts as a hydrophilic agent to retain moisture within the catalyst layer and reduce mass transport out of the catalytic layer.

A layer $(50-250 \mu \mathrm{m}$ thick) of proton conducting membrane is used as a solid polymer electrolyte (SPE). Nafion ${ }^{\circledR}$, which is manufactured by Du Pont ${ }^{\circledR}$, is the commercial standard membrane and it has been widely researched [38, 68-70]. Its chemical structure is based on perfluorinated phosphonic acid copolymer (see Figure 12). Protons are conducted between adjacent acidic groups (- $\left.\mathrm{SO}_{3}-\right)$ attached to the perfluorinated polymer backbone with a proton solvent as a carrier $\left(\mathrm{H}_{2} \mathrm{O}-\mathrm{H}_{3} \mathrm{O}^{+}\right)[71,72]$.

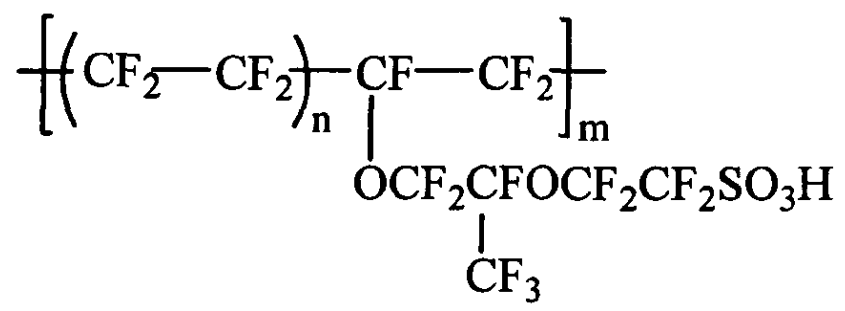

Figure 12: Chemical Structure of Nafion ${ }^{\circledR}$

Nafion ${ }^{\circledR}$ is a popular structure for a membrane due to its high conductivity, good mechanical strength and high chemical and thermal stability which prevents corrosion by evolved oxygen [73-75]. The main drawback of Nafion ${ }^{\circledR}$ membranes is that they are expensive to purchase and its disposal can be expensive due to the fluorine content [70]. Also they are restricted to operating temperatures below the boiling point of water $[76,77]$. They are dependent on 
water to act as a bridge between acidic groups for proton transfer so ionic conductivity is lost at temperatures above $100^{\circ} \mathrm{C}$.

If electrolysis could be operated at higher temperatures electrode kinetics would be enhanced and the process would require less energy due to a reduction in the activation energy barriers [78, 79]. Research groups have been focusing on producing better, less expensive membranes. These include hydrocarbon membranes [80], polybenzimidazoles (PBI), poly(ether ether ketones), (PEEK), poly(ether sulfones) (PES) and sulfonated polyphenyl quinoxaline (SPPQ) $[25,81]$, as well as further development of Nafion®.

\section{Current Collectors}

Porous current collectors (PCC) are metallic plates which transfer electrical current from the separation plates to the electrochemical interfaces the electrolysis cell. They must be highly conductive and highly corrosion resistant to the acidic electrolyte, production of oxygen and high overpotentials. PCCs must have high mechanical strength to give structure to the cell. Mass transfer also takes place across the current collectors [42]; gases must be easily expelled from the current collector and they must allow water to be transported to the catalytic sites through the membrane [45]. Current collectors are generally fabricated from sintered spherically shaped titanium powder [70]. Carbon based materials are not suitable as they cannot withstand the corrosive conditions.

These mass transfer considerations are particularly important at high current densities when mass transfer is the limiting factor. Large porosity enables easy removal of gases, but electron transfer is limited (increasing Ohmic resistance) and less water will be transported to the catalytic layer [42]. At low porosity gas removal is obstructed and channels within the current collector will be blocked, limiting mass transfer [70]. Research previously conducted into the optimisation of porosity showed plate thickness and pore size of sintered titanium 
current collectors. The authors found that for current densities ranging from $0-1 \mathrm{~A} / \mathrm{cm}^{2}$ an optimum pore size of 20 microns is required [42].

\section{Separator Plates}

Separator plates provide the electrolysis cell with structure, which help maintain its stability in varying operating conditions. They also create a pathway for thermal and electron conduction and provide separation between the half-cell reactions. They are highly expensive and are responsible for $48 \%$ of the overall electrolysis stack cost as they are manufactured from expensive materials (titanium or graphite) and aren't produced on a large scale [45]. At high current densities they are responsible for a large contribution to the Ohmic losses, resulting in higher required cell voltages [45].

Titanium is one of the most commonly used materials for plates due to its low initial resistivity, high initial thermal conductivity and low permeability. However over time the titanium corrodes which causes the performance of the cell to decay [82-84]. Graphite is also frequently used due to its high conductivity. However it is expensive, has high corrosion rates and has low strength [84]. To overcome the high costs of titanium and graphite stainless steel has been developed for use as a base material. It has low corrosion resistance so must be coated to resist the acid environment [85].

\section{Costs}

One of the greatest technical challenges to hydrogen production is cost reduction. When considering transport, which has become a key driver for energy independence, hydrogen must be immediately cost-competitive with conventional fuels and technologies on a per-mile basis. This means that the cost of hydrogen (independent of production process), including delivery must AT LEAST be equivalent to the cost of gasoline. The production cost is also 
increased if you take into consideration the purity and application; one such application is a PEM fuel cell.

Concrete figures are difficult to obtain for hydrogen production costs, due to the variation and complexity of feedstocks costs, plant equipment and operating efficiency, and increasing technological advances. In 2007 the US Department of Energy (DoE) projected a cost of $\$ 3.10 / \mathrm{kg}$ from centralised, and $\$ 3.70 / \mathrm{kg}$ from distributed hydrogen production from converting wind energy to hydrogen through electrolysis. A further $\$ 2.00 / \mathrm{kg}$ is estimated for ancillary costs such as compression, storage and dispensing. In the EU a target hydrogen production cost of $€ 9.90 / \mathrm{kgH}_{2}$ in 2015 and $€ 5.50 / \mathrm{kgH}_{2}$ in 2025 across all technologies.

To reduce the cost, research has focused on reducing capital equipment, operations, and maintenance, whilst improving the efficiency of raw material conversion in the various routes to production. Current key research includes developing new hydrogen delivery methods and infrastructure, improving carbon capture technology to ensure that hydrocarbon (coal) based processes release almost no greenhouse gas. Other areas include improving biomass growth, harvesting, and handling to reduce the cost of biomass resources used in hydrogen production. Many studies have been conducted and projections show that hydrogen has a long way to go before it is viable. There remains the argument whether it will e a centralised or a decentralised process and of course this will impact the final production cost. It expected that alternative methods of hydrogen production from bio sources will be more cost effective by 2020 when compared to SMR.

\section{Conclusions}

To conclude this brief overview of hydrogen production technologies, there are many routes to release hydrogen, however it is still almost exclusively an industrial process. Hydrogen has immense potential as an energy vector. However, the hydrogen produced by 
conventional methods suffers from purity issues, which may not be well suited to new applications. In contrast, there is a vast variety of new cleaner technologies entering the field, such as membrane electrolysis that could provide a vital answer to cleaner hydrogen. This high purity hydrogen can thus be deployed in emerging technologies such as fuel cells, in particular in vehicles.

\section{References}

2. Rand, D.A.J., Dell, R. M., Hydrogen Energy - Challanges and Prospects. 2008: The Royal Society of Chemistry.

4. Winter, C.-J., Hydrogen energy -- Abundant, efficient, clean: A debate over the energy-system-of-change. International Journal of Hydrogen Energy, 2009. 34(14, Supplement 1): p. S1-S52.

5. Lemus, R.G. and J.M. Martínez Duart, Updated hydrogen production costs and parities for conventional and renewable technologies. International Journal of Hydrogen Energy, 2010. 35(9): p. 3929-3936.

6. Holladay, J.D., et al., An overview of hydrogen production technologies. Catalysis Today, 2009. 139(4): p. 244-260.

7. Manage, M.N., et al., A techno-economic appraisal of hydrogen generation and the case for solid oxide electrolyser cells. International Journal of Hydrogen Energy, 2011. 36(10): p. 5782-5796.

8. Holladay, J., Hu, J., King, D., Wang, Y., An overview of hydrogen production technologies. Catalysis Today, 2009. 139(4): p. 244-260.

9. Cormos, C.-C., Starr, F., Tzimas, E., Peteves, S., Innovative concepts for hydrogen production processes based on coal gasification with CO2 capture. International Journal of Hydrogen Energy, 2008. 33(4): p. 1286-1294. 
10. Veziroglu, T.N. and S. Sahin, 21st Century's energy: Hydrogen energy system. Energy Conversion and Management, 2008. 49(7): p. 1820-1831.

11. Getoff, N., Photoelectrochemical and photocatalytic methods of hydrogen production: A short review. International Journal of Hydrogen Energy, 1990. 15(6): p. 407-417.

12. Millet, P., et al., Scientific and engineering issues related to PEM technology: Water electrolysers, fuel cells and unitized regenerative systems. International Journal of Hydrogen Energy, 2010.

13. Barbir, F., PEM electrolysis for production of hydrogen from renewable energy sources. Solar Energy, 2005. 78(5): p. 661-669.

14. Harrison, K., Levene, J. I., Electrolysis of Water. 2004, National Renewable Energy Laboratories.

15. Zoulias, E., Varkaraki, E., Lymberopoulos, N., Christodoulou, C. N., Karagioris, G. N., A Review of Water Electrolysis. TCJST, 2004. 4(2): p. 41-71.

16. Floch, P.H., et al., On the production of hydrogen via alkaline electrolysis during offpeak periods. International Journal of Hydrogen Energy, 2007. 32(18): p. 4641-4647.

17. Kreuter, W. and H. Hofmann, Electrolysis: The important energy transformer in a world of sustainable energy. International Journal of Hydrogen Energy, 1998. 23(8): p. 661-666.

18. Ganley, J.C., High temperature and pressure alkaline electrolysis. International Journal of Hydrogen Energy, 2009. 34(9): p. 3604-3611.

19. Gandía, L.M., G. Arzamendi, and P.M. Diéguez, Chapter 1 - Renewable Hydrogen Energy: An Overview, in Renewable Hydrogen Technologies, L.M. Gandía, G. Arzamendi, and P.M. Diéguez, Editors. 2013, Elsevier: Amsterdam. p. 1-17. 
20. Marshall, A.T., et al., Performance of a PEM water electrolysis cell using electrocatalysts for the oxygen evolution electrode. International Journal of Hydrogen Energy, 2007. 32(13): p. 2320-2324.

21. Grigoriev, S.A., V.I. Porembsky, and V.N. Fateev, Pure hydrogen production by PEM electrolysis for hydrogen energy. International Journal of Hydrogen Energy, 2006. 31(2): p. 171-175.

22. Millet, P., et al., PEM water electrolyzers: From electrocatalysis to stack development. International Journal of Hydrogen Energy, 2010. 35(10): p. 5043-5052.

23. Collier, A., et al., Degradation of polymer electrolyte membranes. International Journal of Hydrogen Energy, 2006. 31(13): p. 1838-1854.

24. Millet, P., et al., GenHyPEM: A research program on PEM water electrolysis supported by the European Commission. International Journal of Hydrogen Energy, 2009. 34(11): p. 4974-4982.

25. Linkous, C.A., et al., Development of new proton exchange membrane electrolytes for water electrolysis at higher temperatures. International Journal of Hydrogen Energy, 1998. 23(7): p. 525-529.

26. Grigoriev, S., V. Porembsky, and V. Fateev, Pure hydrogen production by PEM electrolysis for hydrogen energy. International Journal of Hydrogen Energy, 2006. 31(2): p. 171-175.

27. Nieminen, J., I. Dincer, and G. Naterer, Comparative performance analysis of PEM and solid oxide steam electrolysers. International Journal of Hydrogen Energy, 2010. 35(20): p. 10842-10850.

28. Stuart, P.A., et al., Solid oxide proton conducting steam electrolysers. Solid State Ionics, 2008. 179(21-26): p. 1120-1124. 
29. Jin, C., et al., La0.75Sr0.25Cr0.5Mn0.5O3 as hydrogen electrode for solid oxide electrolysis cells. International Journal of Hydrogen Energy, 2011. 36(5): p. 33403346.

30. Ni, M., M. Leung, and D. Leung, Technological development of hydrogen production by solid oxide electrolyzer cell (SOEC). International Journal of Hydrogen Energy, 2008. 33(9): p. 2337-2354.

31. Santos, D.M.F., et al., Platinum-rare earth electrodes for hydrogen evolution in alkaline water electrolysis. International Journal of Hydrogen Energy, 2013. 38(8): p. $3137-3145$.

32. Santos DMF, S.C., Figueiredo JL, Hydrogen production by alkaline water electrolysis. Química Nova, 2013. 36 p. 1176-1193.

33. Lee, T.S., Hydrogen Over potential on Pure Metals in Alkaline Solution. Journal of The Electrochemical Society, 1971. 118(8): p. 1278-1282.

34. Bowen, C.T., et al., Developments in advanced alkaline water electrolysis. International Journal of Hydrogen Energy, 1984. 9(1-2): p. 59-66.

35. Mauer, A.E., D.W. Kirk, and S.J. Thorpe, The role of iron in the prevention of nickel electrode deactivation in alkaline electrolysis. Electrochimica Acta, 2007. 52(11): p. 3505-3509.

36. Zeng, K. and D. Zhang, Recent progress in alkaline water electrolysis for hydrogen production and applications. Progress in Energy and Combustion Science, 2010. 36(3): p. 307-326.

37. Zhou, L. and Y. Cheng, Catalytic electrolysis of ammonia on platinum in alkaline solution for hydrogen generation. International Journal of Hydrogen Energy, 2008. 33(21): p. 5897-5904. 
38. Ursua, A., L.M. Gandia, and P. Sanchis, Hydrogen Production From Water Electrolysis: Current Status and Future Trends. Proceedings of the IEEE, 2012. 100(2): p. 410-426.

39. Kothari, R., D. Buddhi, and R.L. Sawhney, Studies on the effect of temperature of the electrolytes on the rate of production of hydrogen. International Journal of Hydrogen Energy, 2005. 30(3): p. 261-263.

40. Miles, M.H., et al., The oxygen evolution reaction on platinum, iridium, ruthenium and their alloys at $80^{\circ} \mathrm{C}$ in acid solutions. Electrochimica Acta, 1978. 23(6): p. 521526.

41. Renaud, R. and R.L. LeRoy, Separator materials for use in alkaline water electrolysers. International Journal of Hydrogen Energy, 1982. 7(2): p. 155-166.

42. Grigoriev, S.A., et al., Optimization of porous current collectors for PEM water electrolysers. International Journal of Hydrogen Energy, 2009. 34(11): p. 4968-4973.

43. Wei, G., et al., The stability of MEA in SPE water electrolysis for hydrogen production. International Journal of Hydrogen Energy, 2010. 35(9): p. 3951-3957.

44. Pollet, B.G., A novel method for preparing PEMFC electrodes by the ultrasonic and sonoelectrochemical techniques. Electrochemistry Communications, 2009. 11(7): p. 1445-1448.

45. Carmo, M., et al., A comprehensive review on PEM water electrolysis. International Journal of Hydrogen Energy, 2013. 38(12): p. 4901-4934.

46. Yazici, B., et al., Investigation of suitable cathodes for the production of hydrogen gas by electrolysis. International Journal of Hydrogen Energy, 1995. 20(12): p. 957965. 
47. Grigoriev, S.A., et al., Platinum and palladium nano-particles supported by graphitic nano-fibers as catalysts for PEM water electrolysis. International Journal of Hydrogen Energy. In Press, Corrected Proof.

48. Balaji, R., et al., Development and performance evaluation of Proton Exchange Membrane (PEM) based hydrogen generator for portable applications. International Journal of Hydrogen Energy, 2011. 36(2): p. 1399-1403.

49. Chae, S.-Y., et al., Durability study of electrospray deposited Pt film electrode for hydrogen production in PV assisted water electrolysis system. International Journal of Hydrogen Energy, 2011. 36(5): p. 3347-3353.

50. Millet, P., et al., Electrochemical performances of PEM water electrolysis cells and perspectives. International Journal of Hydrogen Energy, 2010.

51. Lessing, P.A., Materials for hydrogen generation via water electrolysis. Journal of Materials Science, 2007. 42(10): p. 3477-3487.

52. Choi, P., A simple model for solid polymer electrolyte (SPE) water electrolysis. Solid State Ionics, 2004. 175(1-4): p. 535-539.

53. Rasten, E., Electrocatalysis in water electrolysis with solid polymer electrolyte*1. Electrochimica Acta, 2003. 48(25-26): p. 3945-3952.

54. Miles, M.H. and M.A. Thomason, Periodic Variations of Overvoltages for Water Electrolysis in Acid Solutions from Cyclic Voltammetric Studies. Journal of The Electrochemical Society, 1976. 123(10): p. 1459-1461.

55. Buckley, D.N. and L.D. Burke, The oxygen electrode. Part 6.-Oxygen evolution and corrosion at iridium anodes. Journal of the Chemical Society, Faraday Transactions 1: Physical Chemistry in Condensed Phases, 1976. 72(0): p. 2431-2440.

56. Balej, J., Electrocatalysts for oxygen evolution in advanced water electrolysis. International Journal of Hydrogen Energy, 1985. 10(2): p. 89-99. 
57. El-Deab, M.S., et al., Enhanced water electrolysis: Electrocatalytic generation of oxygen gas at manganese oxide nanorods modified electrodes. Electrochemistry Communications, 2007.9(8): p. 2082-2087.

58. S., G., Performance of supported catalysts for water electrolysis, in Norwegian University of Science and Technology. 2012.

59. Matsumoto, Y. and E. Sato, Electrocatalytic properties of transition metal oxides for oxygen evolution reaction. Materials Chemistry and Physics, 1986. 14(5): p. 397-426.

60. Ma, L., S. Sui, and Y. Zhai, Investigations on high performance proton exchange membrane water electrolyzer. International Journal of Hydrogen Energy, 2009. 34(2): p. $678-684$.

61. Su, H., et al., Performance Investigation of Membrane Electrode Assemblies for Hydrogen Production by Solid Polymer Electrolyte Water Electrolysis. International Journal of Electrochemical Science, 2012. 7(5).

62. Marshall, A., et al., Hydrogen production by advanced proton exchange membrane (PEM) water electrolysers-Reduced energy consumption by improved electrocatalysis. Energy, 2007. 32(4): p. 431-436.

63. Song, S., et al., Electrochemical investigation of electrocatalysts for the oxygen evolution reaction in PEM water electrolyzers. international journal of hydrogen energy, 2008. 33(19): p. 4955-4961.

64. Zhang, Y., et al., Study on a novel manufacturing process of membrane electrode assemblies for solid polymer electrolyte water electrolysis. Electrochemistry Communications, 2007. 9(4): p. 667-670.

65. Siracusano, S., et al., Optimization of components and assembling in a PEM electrolyzer stack. International Journal of Hydrogen Energy, 2011. 36(5): p. 33333339. 
66. Mayousse, E., et al., Synthesis and characterization of electrocatalysts for the oxygen evolution in PEM water electrolysis. International Journal of Hydrogen Energy, 2011. 36(17): p. 10474-10481.

67. $\mathrm{Xu}, \mathrm{W}$. and $\mathrm{K}$. Scott, The effects of ionomer content on PEM water electrolyser membrane electrode assembly performance. International Journal of Hydrogen Energy, 2010. 35(21): p. 12029-12037.

68. Millet, P., et al., Electrochemical performances of PEM water electrolysis cells and perspectives. International Journal of Hydrogen Energy, 2011. 36(6): p. 4134-4142.

69. Goñi-Urtiaga, A., D. Presvytes, and K. Scott, Solid acids as electrolyte materials for proton exchange membrane (PEM) electrolysis: Review. International Journal of Hydrogen Energy, 2012. 37(4): p. 3358-3372.

70. Ito, H., et al., Properties of Nafion membranes under PEM water electrolysis conditions. International Journal of Hydrogen Energy, 2011. 36(17): p. 10527-10540.

71. Mauritz, K.A. and R.B. Moore, State of understanding of Nafion. Chemical reviews, 2004. 104(10): p. 4535-4586.

72. Kreuer, K.-D., Proton conductivity: materials and applications. Chemistry of Materials, 1996. 8(3): p. 610-641.

73. Bose, S., et al., Polymer membranes for high temperature proton exchange membrane fuel cell: Recent advances and challenges. Progress in Polymer Science, 2011. 36(6): p. $813-843$.

74. Smitha, B., S. Sridhar, and A.A. Khan, Solid polymer electrolyte membranes for fuel cell applications—a review. Journal of Membrane Science, 2005. 259(1-2): p. 10-26.

75. Peighambardoust, S.J., S. Rowshanzamir, and M. Amjadi, Review of the proton exchange membranes for fuel cell applications. International Journal of Hydrogen Energy, 2010. 35(17): p. 9349-9384. 
76. Ivanchev, S.S., Fluorinated proton-conduction nafion-type membranes, the past and the future. Russian Journal of Applied Chemistry, 2008. 81(4): p. 569-584.

77. Wen, S., et al., Sulfonated poly(ether sulfone) (SPES)/boron phosphate (BPO4) composite membranes for high-temperature proton-exchange membrane fuel cells. International Journal of Hydrogen Energy, 2009. 34(21): p. 8982-8991.

78. Hauch, A., et al., Highly efficient high temperature electrolysis. Journal of Materials Chemistry, 2008. 18(20): p. 2331-2340.

79. Li, Q., et al., Approaches and Recent Development of Polymer Electrolyte Membranes for Fuel Cells Operating above $100{ }^{\circ} \mathrm{C}$. Chemistry of Materials, 2003. 15(26): p. 4896-4915.

80. Masson, J.P., et al., Obtention and evaluation of polyethylene-based solid polymer electrolyte membranes for hydrogen production. International Journal of Hydrogen Energy, 1982. 7(2): p. 167-171.

81. Wei, G., et al., SPE water electrolysis with SPEEK/PES blend membrane. International Journal of Hydrogen Energy, 2010. 35(15): p. 7778-7783.

82. Jung, H.-Y., et al., Performance of gold-coated titanium bipolar plates in unitized regenerative fuel cell operation. Journal of Power Sources, 2009. 194(2): p. 972-975.

83. Wang, S.-H., J. Peng, and W.-B. Lui, Surface modification and development of titanium bipolar plates for PEM fuel cells. Journal of Power Sources, 2006. 160(1): p. 485-489.

84. Tawfik, H., Y. Hung, and D. Mahajan, Metal bipolar plates for PEM fuel cell-A review. Journal of Power Sources, 2007. 163(2): p. 755-767.

85. Wang, H., M.A. Sweikart, and J.A. Turner, Stainless steel as bipolar plate material for polymer electrolyte membrane fuel cells. Journal of Power Sources, 2003. 115(2): p. 243-251. 
